\title{
HYPERURICEMIA IN SYSTEMIC HYPERTENSION AND ITS CORRELATION WITH SYSTOLIC AND DIASTOLIC BLOOD PRESSURE.
}

\footnotetext{
1. MBBS, M. Phil, FCPS

Associate Professor

Faculty of Medicine and Allied

Medical Sciences

Isra University, Hyderabad, Sindh,

Pakistan.

2. MBBS, M. Phil, Ph.D

Associate Professor

Department of Biochemistry

Indus Medical College

Tando Muhammad Khan, Sindh.

3. MBBS, M. Phil

Assistant Professor

Department of Biochemistry,

Bilawal Medical College, LUMHS,

Jamshoro, Sindh, Pakistan.

4. MBBS, M.Phil

Assistant Professor

Department of Anatomy

Isra University, Hyderabad, Sindh,

Pakistan.
}

Correspondence Address:

Dr. Haji Khan Khoharo

Faculty of Medicine and Allied Medica

Sciences

Isra University, Hyderabad, Sindh,

Pakistan.

drhajikhan786@gmail.com

Article received on:

04/01/2019

Accepted for publication:

$18 / 05 / 2019$

\begin{abstract}
Haji Khan Khoharo', Ali Akbar Shah², Fatima Qureshi ${ }^{3}$, Sajjad Ali Almani ${ }^{4}$
ABSTRACT... Objectives: To determine the serum uric acid (SUA) in systemic hypertension and its correlation with systolic (SBP) and diastolic blood pressure (DBP). Study Design: Cross sectional study design. Setting: Department of Medicine, Isra University Hospital. Period: From April 2016 - February 2017. Material and Methods: A sample of 100 cases of systemic hypertension and 100 age, gender, body weight and BMl controls were selected through nonprobability purposive sampling. Volunteers were asked for history, physical examination, and blood sampling. Systemic BP was measured with a mercury sphygmomanometer. 2 ml venous blood was taken, centrifuged and sera were used for detection of SUA. Data was saved in a prestructured Performa. Computed based statistical software (SPSS v 22.0, IBM, Incorporation, USA) was used for data analysis. Data variables were analyzed at $95 \% \mathrm{Cl}(\mathrm{P} \leq 0.05)$. Results: Serum uric acid in controls was $2.91 \pm 0.75 \mathrm{mg} / \mathrm{dl}$ compared to $5.70 \pm 1.76 \mathrm{mg} / \mathrm{dl}(\mathrm{P}=0.0001)$. $57 \%$ of cases revealed hyperuricemia compared to $11 \%$ in control $\left(X^{2}=17.5, P=0.0001\right)$. Serum Uric acid showed significantly positive correlation with Systolic BP $\left(r=0.518^{\star}, p=0.0001\right)$ and Diastolic BP $\left(r=0.397^{\star *}, p=0.0001\right)$. Conclusion: The present study reports hyperuricemia in $57 \%$ cases of systemic hypertension and uric acid shows positive correlation with systolic and diastolic blood pressure.
\end{abstract}

Key words: $\quad$ Diastolic BP, Hyperuricemia, Systemic Hypertension, Systolic BP.

Article Citation: Khoharo HK, Shah AA, Qureshi F, Almani SA. Hyperuricemia in Systemic Hypertension and its correlation with systolic and diastolic blood pressure. Professional Med J 2020; $27(1): 89-93$ DOI: 10.29309/TPMJ/2020.27.1.3345

\section{INTRODUCTION}

Economic prosperity of communities have created new health problems of metabolic concern such as the hyperuricemia and systemic hypertension. ${ }^{1}$ Both are related to each other through weight gain and increased metabolic process. In developing countries, the use of meat increases the body weight and is related to the increased uric acid levels in the blood vessels. Systemic hypertension has become a major public health problem in the urban communities of developing countries. ${ }^{1,2}$ Systemic hypertension is a risk for morbid health owing to increased risk of myocardial infarction, cardiac failure, renal failure, cerebrovascular disorders, and the peripheral arterial disease (PAD). ${ }^{1}$ Estimates shows the total world burden of subjects suffering from systemic hypertension approximates to 1 billion people and 7.1 million deaths. World Health Organization (WHO) estimates shows that systolic blood pressure (SBP) rise of $>115 \mathrm{~mm}$ $\mathrm{Hg}$ increases $49 \%$ risk of ischemic heart disease (IHD) and $62 \%$ of brain strokes. Estimates show approximately $30 \%$ hypertension cases are undiagnosed. A $40 \%$ drug non- compliance has been reported that increases the risk of related systemic complications. Optimal control is reported in $40 \%$ hypertension cases and remaining $60 \%$ hypertension cases don't have proper control of systemic hypertension. ${ }^{2}$ One of the metabolic disorder of hyperuricemia has been reported in systemic hypertension cases. Pre-hypertension shows predilection for the hyperuricemia too. Previous studies ${ }^{3,4}$ reported correlation of hyperuricemia and risk of systemic hypertension. Hyperuricemia has been linked to microalbuminuria in systemic hypertension and pre- hypertension. ${ }^{2}$ Hyperuricemia has been reported as a risk factor for the systemic hypertension. ${ }^{2-5}$ Previous studies ${ }^{5,6}$ reported 
$25-50 \%$ of systemic hypertension cases show hyperuricemia. Hyperuricemia is now an established risk factor for the insulin resistance, weight gain and obesity, hyperlipidemia and dyslipidemia, kidney and systemic hypertension. Previous studies ${ }^{2-6}$ reported rising prevalence of hyperuricemia in low and middle-income countries populations. Many of previous studies ${ }^{3-7}$ had reported correlation of hyperuricemia, systemic hypertension and obesity. Since research is lacking regarding the association of serum uric acid and systemic hypertension in Pakistan, this motivated the researcher to conduct the present study. The present study was planned to determine the serum uric acid in systemic hypertension in particular to its correlation with systolic blood pressure (SBP) and diastolic blood pressure (DBP) in patients presenting at our tertiary care hospital.

\section{SUBJECTS AND METHODS}

The present case control study was conducted at the Department of Medicine, Isra University Hospital from April 2016 - February 2017. A sample of 100 cases of systemic hypertension and 100 age, gender, body weight and BMI controls were selected through non-probability purposive sampling. Rao-software was used for sample size calculation. Patients were collected from both in- patient and out- patient departments. Volunteers were asked for history, physical examination, and blood sampling. Clinical history was taken to ascertain the inclusion and exclusion criteria. Biodata was entered in a pre-structured Performa. Inclusion criteria were; diagnosed cases of systemic hypertension, age range $40-60$ years and male gender only. Systemic hypertension was defined as per JNC- VII criteria. While exclusion criteria were; female gender, secondary hypertension, hyperthyroidism, diabetes mellitus and other endocrine disorders, Ischemic heart disease, pregnancy, kidney disease, alcoholics and thiazide drug intake. Systemic BP was measured with a mercury sphygmomanometer. Blood pressure measured after 5 minutes rest in sitting position. Three readings were taken for both systolic and diastolic BP when the patients were sitting comfortably. Body weight was measured on an electric weight machine. BMl was calculated by body weight $(\mathrm{Kg}) /$ height $\left(\mathrm{m}^{2}\right)$. $2 \mathrm{ml}$ venous blood was taken, centrifuged and sera were used for detection of SUA. Samples were centrifuged for 15 minutes at $\times 3000 \mathrm{rpm}$ to separate the sera. Sera were stored in Eppendorf tubes and if necessary were stored at $-20^{\circ} \mathrm{C}$. Data was saved in a pre- structured Performa. Ethical approval was taken in advance and verbal consent of participants was mandatory. Computed based statistical software (SPSS v 22.0, IBM, Incorporation, USA) was used for data analysis. Student's t test and Chi $\left(\mathrm{x}^{2}\right)$ square tests analyzed the continuous and categorical variables respectively. Pearson's correlation bivariate method was used for association of uric acid with systolic and diastolic BP, age and body weight. All data were analyzed at $95 \% \mathrm{Cl}$ $(P \leq 0.05)$.

\section{RESULTS}

Age of controls and cases was $51.1 \pm 6.83$ and $49.97 \pm 6.72$ years respectively $(P=0.051)$ (Table-I). Body weight and BMI 77.4 \pm 12.2 vs. $78.5 \pm 13.9 \mathrm{Kg}(P=0.57)$ and $27.53 \pm 3.30$ and $28.48 \pm 3.61 \mathrm{~kg} / \mathrm{m}^{2}$ in control and cases respectively $(P=0.0001)$. Systolic and Diastolic BP showed highly significant differences between control and cases $(P=0.0001)$. Serum uric acid (SUA) shows statistically significant difference between control and cases. SUA in controls was $2.91 \pm 0.75$ compared to $5.70 \pm 1.76 \mathrm{mg} / \mathrm{dl}$ $(P=0.0001) .57 \%$ of cases revealed hyperuricemia compared to $11 \%$ in control $\left(X^{2}=17.5, P=0.0001\right)$ Table-II. Pearson's correlation analysis results are shown in Table-III. Serum Uric acid showed significantly positive correlation with Systolic BP $\left(r=0.518^{*}, p=0.0001\right)$ and Diastolic BP $(r=$ $\left.0.397^{\star *}, p=0.0001\right)$. However, the age $(r=0.106$ $p=0.135)$ and body weight $(r=0.09 p=0.90)$ showed highly non-significant correlation. Significant correlation was defined at the 0.01 level (2-tailed). 


\begin{tabular}{|l|c|c|c|}
\hline & Control $(\mathbf{n}=\mathbf{1 0 0})$ & Cases $\mathbf{( n = 1 0 0 )}$ & P-Value \\
\hline Age (years) & $51.1 \pm 6.83$ & $49.97 \pm 6.72$ & 0.051 \\
\hline Body weight $(\mathrm{kg})$ & $77.4 \pm 12.2$ & $78.5 \pm 13.9$ & 0.57 \\
\hline BMI $\left(\mathrm{kg} / \mathrm{m}^{2}\right)$ & $27.53 \pm 3.30$ & $28.48 \pm 3.61$ & 0.0001 \\
\hline Systolic BP $(\mathrm{mmHg})$ & $130.58 \pm 8.54$ & $145.8 \pm 21.2$ & 0.0001 \\
\hline Diastolic BP $(\mathrm{mmHg})$ & $70.85 \pm 8.52$ & $80.4 \pm 14.8$ & 0.0001 \\
\hline Uric acid $(\mathrm{mg} / \mathrm{dl})$ & $2.91 \pm 0.75$ & $5.70 \pm 1.76$ & 0.0001 \\
\hline
\end{tabular}

Table-I. Demographic and laboratory findings of control and cases

\begin{tabular}{|l|c|c|c|c|}
\hline & Control $(\mathbf{n}=\mathbf{1 0 0})$ & Cases $(\mathbf{n = 1 0 0 )}$ & $\mathbf{X}^{2}$-Value & P-Value \\
\hline Normouricemia & $89 \%$ & $43 \%$ & 17.5 & 0.0001 \\
\hline Hyperuricemia & $11 \%$ & $57 \%$ & & \\
\hline
\end{tabular}

Table-II. Hyperuricemia among control and cases

\begin{tabular}{|c|c|c|}
\hline & r-Value & P-value \\
\hline Systolic BP (mmHg) & $0.518^{\star}$ & 0.0001 \\
\hline Diastolic BP(mmHg) & $0.397 * \star$ & 0.0001 \\
\hline Age (years) & $0.106^{\star}$ & 0.135 \\
\hline Body weight (kg) & $0.09 *$ & 0.90 \\
\hline \multicolumn{3}{|c|}{$\begin{array}{l}\text { Table-III. Pearson's correlations of Uric acid in cases } \\
* * \text { Correlation is significant at the } 0.01 \text { level (2-tailed) }\end{array}$} \\
\hline
\end{tabular}

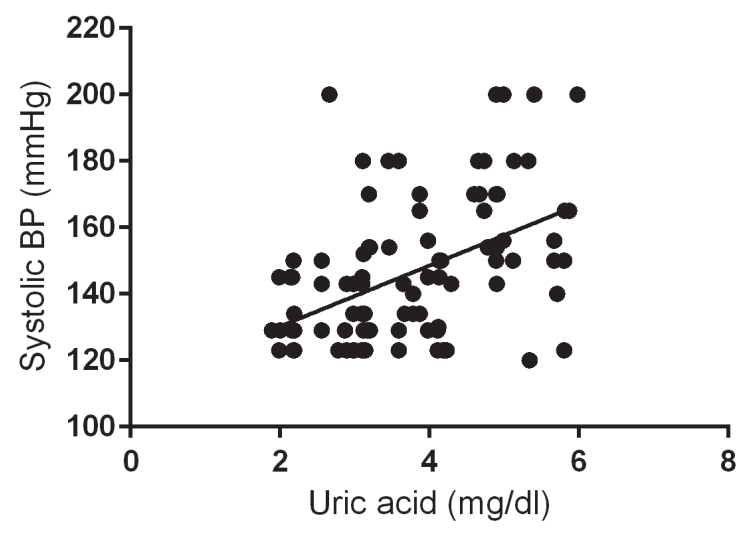

Figure-1. Uric acid shows significant correlation with Systolic BP $(r=0.518, P=0.0001)$

\section{DISCUSSION}

The present case control study is the first to report the serum uric acid (SUA) in systemic hypertension and its correlation with Systolic (SBP) and Diastolic blood pressure (DBP) from our tertiary care hospital. The present case control study analyzed SUA of essential hypertensive patients compared to control. The control subjects matched with cases in terms of age, gender, BMI and body weight (Bwt) as confounding variables to exclude the bias. Our

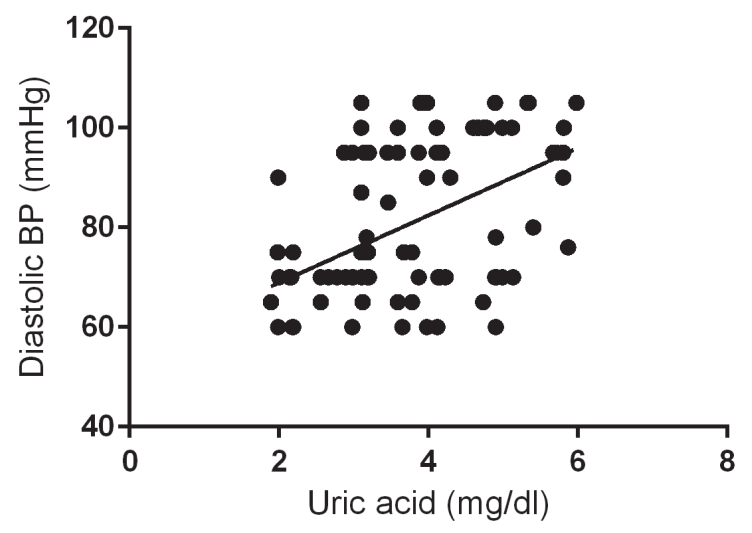

Figure-2. Uric acid shows significant correlation with Diastolic BP $(r=0.397, p=0.0001)$

control and cases belonged to old age of $40-60$ years. Age of controls and cases was $51.1 \pm 6.83$ and $49.97 \pm 6.72$ years respectively $(P=0.051)$ (Table-l). The finding of age of present study is in agreement with previous studies ${ }^{3-10}$ that reported the similar age range of their study subjects. They reported that the essential hypertensive of this age is common, hence our age range of $40-60$ years is a clinically important finding. Many of previous studies $^{11-13}$ had reported essential hypertension is common in the age range of $40-60$ years. Lee et 
$\mathrm{al}^{15}$ reported majority of study cases of essential hypertension were in the range of 40-50 years, that is also in full agreement to the present study. However, age contradicts to a Pakistani study of Habib et $\mathrm{al}^{14}$ has reported minimum age of 20 years that contradicts with the present study. Body weight and BMI $77.4 \pm 12.2$ vs. $78.5 \pm 13.9$ $\mathrm{Kg}(\mathrm{P}=0.57)$ and $27.53 \pm 3.30$ and $28.48 \pm 3.61 \mathrm{~kg} /$ $\mathrm{m}^{2}$ in control and cases respectively $(\mathrm{P}=0.0001)$. Systolic and Diastolic BP showed highly significant differences between control and cases $(\mathrm{P}=0.0001)$. In present study, hyperuricemia was noted in $57 \%$ cases of systemic hypertension. Frequency of hyperuricemia of $57 \%$ of present study is supported by previous studies. ${ }^{5,6}$ Mean \pm SD serum uric acid showed significant difference between control and cases. SUA in controls was $2.91 \pm 0.75$ compared to $5.70 \pm 1.76 \mathrm{mg} /$ dl $(P=0.0001)$. The findings are in agreement with previous studies. ${ }^{12,13}$ However, a previous study ${ }^{11}$ reported the serum uric acid in cases and control were very high i.e. $6.18 \pm 1.79 \mathrm{mg} / \mathrm{dl}$ vs. $5.60 \pm 1.83 \mathrm{mg} / \mathrm{dl}$ respectively $(p<0.05)$. The differences are most probably due to the dietary habits and living patterns of study subjects. A previous study ${ }^{12}$ reported high levels serum uric acid in systemic hypertension in Pakistani adult population. This previous study ${ }^{12}$ reported mean uric acid of $316.87 \mu \mathrm{mol} / \mathrm{L}$ and $273.24 \mu \mathrm{mol} / \mathrm{L}$ in cases and control respectively. The findings corroborate to the SUA in controls $2.91 \pm 0.75$ vs. $5.70 \pm 1.76 \mathrm{mg} / \mathrm{dl}(\mathrm{P}=0.0001)$ in the present study. Another previous study ${ }^{14}$ reported similar findings of hyperuricemia in pre-hypertension and hypertension. This previous study reported SUA (mean \pm SD) of $4.91 \pm 0.88 \mathrm{mg} / \mathrm{dl}$ in control, $5.89 \pm 0.97$ in pre-hypertension $\mathrm{mg} / \mathrm{dl}$ and 6.56 $\pm 0.64 \mathrm{mg} / \mathrm{dl}$ in hypertension respectively. A previous study ${ }^{15}$ reported significant high SUA in hypertensive subjects compared to controls. Serum uric acid in systemic hypertension patients in present study was noted as $5.70 \pm 1.76 \mathrm{mg} / \mathrm{dl}$ that is in agreement with previous study that found 5.8 $\mathrm{mg} / \mathrm{dl}$ in hypertensive patients $(P<0.05)$. Vakil et $\mathrm{al}^{16}$ has reproved similar findings of hyperuricemia in systemic hypertension comparable to the present study. In the present study, serum uric acid was analyzed in systemic hypertension with especial reference to its correlation with systolic and diastolic BP. We report serum uric acid was high in systemic hypertension patients and it showed positive correlation with systolic and diastolic BP. Serum Uric acid showed significantly positive correlation with Systolic BP $\left(r=0.518^{*}\right.$, $p=0.0001)$ and Diastolic BP $\left(r=0.397^{\star *}\right.$, $p=0.0001)$. However, the age $(r=0.106 p=0.135)$ and body weight $(r=0.09 p=0.90)$ showed highly non-significant correlation. Significant correlation was defined at the 0.01 level (2-tailed). Study by Vakil et $\mathrm{al}^{16}$ reported positive correlation of SUA and systemic hypertension similar to the present study. Our findings are also concordant to previous studies. ${ }^{17-19}$ They ${ }^{17-19}$ reported hyperuricemia among systemic hypertension. The only limitation of present study is small group of study subjects related to peculiar ethnicity hence findings cannot be generalized for others. Strength of study is based on its prospective study design and patients selection according to inclusion and exclusion. However, cause-effect relationship of hyperuricemia and systemic hypertension cannot be ascertained due to case control study design. The present study concludes the patients of essential hypertension must be screened for serum uric acid levels.

\section{CONCLUSION}

The present study reports hyperuricemia in 57\% cases of systemic hypertension and uric acid shows positive correlation with systolic and diastolic blood pressure. Large scale studies are recommended to establish the cause-effect relationship of hyperuricemia and systemic hypertension in the indigenous population of the country. Serum uric acid should be measured in systemic hypertension patients.

\section{Copyright $@ 18$ May, 2019.}

\section{REFERENCES}

1. Birgisdottir $\mathrm{KH}$, Jonsson $\mathrm{SH}$, Asgeirsdottir TL. Economic conditions, hypertension, and cardiovascular disease: Analysis of the Icelandic economic collapse. Health Econ Rev 2017; 7(1):20.

2. Shafi ST, Shafi T. A survey of hypertension prevalence, awareness, treatment, and control in health screening camps of rural central Punjab, Pakistan. J Epidemiol Glob Health 2017; 7(2):135-40. 
3. Qabulio SN, Shahnawaz S, Mansoor K, Jadoon A, Akhter $S$, Tanwir F. Increased serum uric acid association with Hypertension. Emerg Med Inves 2017: EMIG-143.

4. Ali N, Perveen R, Rahman S, Mahmood S, Rahman $S$, Islam S. Prevalence of hyperuricemia and the relationship between serum uric acid and obesity: $A$ study on Bangladeshi adults. PLOS ONE 2018; 13(11): e0206850:1-12.

5. Fouad M, Fathy $H$, Zidan A. Serum uric acid and its association with hypertension, early nephropathy and chronic kidney disease in type 2 diabetic patients. J Bras Nefrol 2016; 38 (4):403-10.

6. Ansari RN, Gandhi RV, Saiyed MN, Jain KD. Study of prevalence and impact of hyperuricemia in a patient of hypertension.Int J Adv Med 2017; 4:367-9.

7. Anand NN, Padma V, Prasad A, Alam KC, Javid MS. Serum uric acid in new and recent onset primary hypertension. J Pharm Bioallied Sci 2015; 7 (Suppl 1):S4-8.

8. Acevedo A, Benavides J, Chowdhury M, Lopez M, Pena L, Montegegro A, et al. Hyperuricemia and cardiovascular disease in patients with hypertension. Con Med 2016; 80 (2): 85- 90.

9. Castro- Torres Y, Khan NY, Carmona- Puerta RC. Levels of uric acid and increased diastolic blood pressure: Risk factors for atrial fibrillation in patients older than 60 years. Rev Assoc Med Bras 2017; 63(7):600-5.

10. Kanwar G, Kabra R. Serum uric acid level and obesity: An association. Int`I J Healthcare Sci 2016; 4(1):52-55.
11. Divyen K, Aundhakar SC, Sutariya NL, Vartika R, Hardik $P$. Evaluation of roleserum uric acid levels in cases of essential hypertension. Int'I J Contemp Med Res 2018; 5(5):E18-E21.

12. Habib MS, Khatoon S, Sand AA. Hyperuricemia; A risk factor for development of hypertension in Pakistani community. Professional Med J 2018; 25(3):381-386.

13. Lee JJ, Ahn J, Hwang J. Relationship between uric acid and blood pressure in different age groups. Clin Hypert 2015; 21:14.

14. Shrivastav C, Sharma S, Suhalka ML, Kaur M. Hyperuricaemia and essential hypertension: A case control study in Southern Rajasthan. Int J Res Med Sci 2016; 4:78-83.

15. Neki NS, Tamilmani NS. A study of serum uric acid level in essential hypertension. JIMSA 2015; 28 No. 1.

16. Vakil A, Vrkariya P, Barafiwala V, Gamit K, Patel D, Doctor N. Study of serum uric acid level in hypertension. IOSR J Dent Med Sci 2017; 16: 69-73.

17. Ahmed S, Shaffique S, Asif M, Hussain G, Ahmed K. Pathophysiology, clinical consequences, epidemiology and treatment of hyperuricemia gout. RADS J Pharm Pharm Sci 2018; 6(1):88-94.

18. Kansui Y, Ohtsubo T, Goto K, Sakata S, Ichishima K, Fukuhara $\mathrm{M}$, et al. Association of serum uric acid with blood pressure in Japanese men. Cross-sectional study in work-site group. Circ J 2011; 75:2827-32.

19. Zhang W, Sun K, Yang Y, Zhang H, Hu FB, et al. Plasma uric acid and hypertension in a Chinese community: Prospective study and meta analysis. Clin Chem 2009; 55: 2026-2034.

\begin{tabular}{|c|c|c|c|}
\hline \multicolumn{3}{|c|}{ AUTHORSHIP AND CONTRIBUTION DECLARATION } \\
\hline Sr. \# & Author(s) Full Name & \multicolumn{1}{|c|}{ Contribution to the paper } \\
\hline 1 & Haji Khan Khoharo & $\begin{array}{l}\text { Litearture review, Concept, materials } \\
\text { handling, interpretation lab investigations, } \\
\text { Manuscript write up, Proof reading. } \\
\text { Concept, Materials handling, Interpretation } \\
\text { lab investigations, Manuscript write up, } \\
\text { Proof reading. } \\
\text { Literature review, Materials handling, } \\
\text { compilation of results, statistical analysis, } \\
\text { Manuscript write up, Proof reading, } \\
\text { Correspondance. } \\
\text { Concept, Materials handling, Collection of } \\
\text { materials, compilation of resutls, statistical } \\
\text { analysis, manuscript write up. }\end{array}$ \\
\hline 3 & Ali Akbar Shah & Fatima Qureshi & Sajjad Ali Almani
\end{tabular}

